\title{
In-house validation method for quantification of amoxicillin in medicated feedingstuffs with the use of HPLC-DAD technique
}

\author{
Ewelina Patyra ${ }^{\bowtie}$, Krzysztof Kwiatek \\ Department of Hygiene of Animal Feedingstuffs, \\ National Veterinary Research Institute, 24-100 Puławy, Poland \\ ewelina.patyra@piwet.pulawy.pl
}

Received: December 9, 2019

Accepted: June 10, 2020

\begin{abstract}
Introduction: A high-performance liquid chromatographic-diode array detector (HPLC-DAD) method for the determination of amoxicillin in medicated feedingstuffs was developed and validated. The method was used to investigate the quality requirements of animal feedingstuffs (declared content of active substance and feed homogeneity). Material and Methods: Twogram samples were extracted by potassium phosphate buffer solution. Extracts were filtered and directly analysed by HPLC-DAD without further clean-up. Amoxicillin was separated by acetonitrile and $0.01 \mathrm{M}$ phosphate buffer (pH 5.0) on a Phenomenex Luna C18 column. Results: This method provided average recoveries of 76.1 to $81.6 \%$ with coefficients of variation (CV, \%) for repeatability and reproducibility in the ranges of 3.7-7.2\% and 5.3-7.6\%, respectively. The limit of detection was $51.2 \mathrm{mg} / \mathrm{kg}$ and limit of quantification was $103.0 \mathrm{mg} / \mathrm{kg}$. Conclusion: The method was successfully validated and proved to be efficient, precise, and useful for quantification of amoxicillin in medicated feedingstuffs.
\end{abstract}

Keywords: high performance liquid chromatography, diode array detector, medicated feedingstuffs, amoxicillin, validation.

\section{Introduction}

Antibiotics are substances able to kill or inhibit the growth of microorganisms which are produced by living organisms but which can also be produced synthetically $(4,31)$. Antibiotics have been used on a large scale for several decades in human medicine and as growth promoters in veterinary medicine (26). They can be administered to animals by injection, intrauterine and intramammary infusion, orally in water or feed, and topically (24). Theoretically, all of these routes may lead to the appearance of residues in food of animal origin which are of concern due to their implication in the development of antibiotic resistance of target pathogens, induced allergic reactions in some hypersensitive individuals, potential compromise of the human intestinal and immune systems $(24,26)$.

According to the Ninth ESVAC Report, sales of veterinary antimicrobial agents, in the European Union ranged from 3.1 to 423.1 milligrams sold per population correction unit (mg/PCU) across 31 countries. Penicillins (1,787 mg/PCU), tetracyclines (2,019 $\mathrm{mg} / \mathrm{PCU})$, and sulphonamides (608 mg/PCU) accounted for $67 \%$ of the total sales in 2017 (10). These antibacterial substances are used in food production animals and can be administered through medicated feed. These feedstuffs must undergo regular checks, including appropriate laboratory tests of homogeneity by the manufacturers to ensure that they comply with the requirements of Regulation (EU) 2019/4 of the European Parliament and of the Council of 11 December 2018, especially with respect to their homogeneity, declaration of contents, storage conditions, and stability (29).

One of the antibiotics which can be used in medicated feed is amoxicillin (AMO). Amoxicillin is a semi-synthetic penicillin widely used in clinical therapy as a broad-spectrum bactericidal compound. It inhibits peptidoglycan synthesis at the bacterial cell wall and has fast bactericidal action (9). Amoxicillin is used to treat bacterial infections in pigs and poultry. This 
group is administered orally either by water or in medicated feeds, the latter appearing to be more suitable than medicated water because the stability of AMO in aqueous solution is poor and medicated water must be freshly prepared every $6-12 \mathrm{~h}$. For this reason, amoxicillin is more often given to pigs as medicated feed (9).

The official methods of the Association of American Feed Control Officials (AAFCO) and the Association of Official Analytical Chemists (AOAC) for the analysis of penicillins in medicated feed samples are based on microbiological plate assays, but these methods are time consuming and not very specific because they do not allow pertinent distinctions, e.g. of ampicillin from amoxicillin (2). Micellar electrokinetic capillary chromatography (18) or capillary electrophoresis $(8,20,25)$ are techniques used for the determination of penicillins in feeds. Many chromatographic methods with fluorescence detection (FLD) or UV detection $(1,4,11,12,16,17,19,21,22)$, liquid chromatography-mass spectrometry (LC-MS) (5, $6,9,14,19,23)$ or ultra-high performance liquid chromatography-mass spectrometry $(5,7,33)$ are also used for the determination of penicillins in food of animal origin.

In Poland amoxicillin is licensed as a veterinary drug for use in feed for pigs and is applied in a dose of 300 or $400 \mathrm{mg} / \mathrm{kg}$ feed. AMO is commonly used as an active substance in medicated feedingstuffs so we developed a rapid simple and selective method for quantitative analysis of amoxicillin in medicated feed for pigs based on its extraction from the matrix by phosphate buffer extraction and determination by highperformance liquid chromatography HPLC with a diode array detector (HPLC-DAD).

\section{Material and Methods}

Chemicals and reagents. Amoxicillin sodium salt was bought from Sigma Aldrich (St. Louis, MO, USA), potassium dihydrogen phosphate $\left(\mathrm{KH}_{2} \mathrm{PO}_{4}\right)$ was obtained from Merck (Darmstadt, Germany), and HPLC-grade acetonitrile was purchased from J.T. Baker (Landsmeer, the Netherlands). All reagents used were of analytical grade and analytically pure. Purified water was prepared in-house with a Milli-Q water system from Millipore (Burlington, MA, USA).

Standard solution. A stock standard solution of amoxicillin $(2 \mathrm{mg} / \mathrm{mL})$ was freshly prepared in Milli-Q water before analysis.

Calibration curves. Standard calibration curves were prepared by adding different volumes of amoxicillin standard solution to $0.05 \mathrm{M}$ phosphate buffer, at $\mathrm{pH}$ 4.5. The standards were prepared at concentrations of $0.03,0.04,0.06,0.08$, and $0.1 \mathrm{mg} / \mathrm{mL}$ of AMO. These solutions were analysed by HPLC-DAD and a calibration curve was plotted.
HPLC-DAD analysis. An HPLC system consisting of an HP 1100 Series (Agilent Technologies, Santa Clara, CA, USA) equipped with a quaternary pump with four solvent channels, degasser system, automatic injector, column thermostat, and diode array detector was used for the analysis. The chromatographic conditions were chosen in terms of peak shape, column efficiency, retention time, resolution, and sensitivity. Separations were performed on a reverse-phase C18 column $(250 \mathrm{~mm} \times 4.6 \mathrm{~mm}, 5.0 \mu \mathrm{m}$ silica $)$ from Phenomenex (Torrance, CA, USA), maintained at $35^{\circ} \mathrm{C}$. The flow rate was $1 \mathrm{~mL} / \mathrm{min}$ and injection volume $20 \mu \mathrm{L}$. The composition of mobile phases A and B was set as $0.01 \mathrm{M}$ phosphate buffer, $\mathrm{pH} 5.0$ (A) and acetonitrile (B). The gradient elution started from 1.5\% of solvent B at $0 \mathrm{~min}, 40 \%$ from 4.0 to $14.0 \mathrm{~min}$, the same from 14.01 to $19.0 \mathrm{~min}, 1.5 \%$ of solvent B from 19.01 to $20.0 \mathrm{~min}$, and this was held from $20.1 \mathrm{~min}$ to $25 \mathrm{~min}$ with a total analysis run time of $25 \mathrm{~min}$. Amoxicillin was eluted within $18 \mathrm{~min}$. Detection with the diode array was carried out at $202 \mathrm{~nm}$.

Sample preparation and extraction. Ground feed sample (2 g) was weighed accurately into a $50 \mathrm{~mL}$ polypropylene centrifuge tube. Selected blank samples were spiked with known quantities of AMO to serve as quality control samples and to be made use of in evaluation of the method recovery and precision in the validation procedure. After that, the samples were shaken on a vortex mixer and the mixture allowed to stand overnight at room temperature to enable sufficient equilibration with the feed matrix. Then, $10 \mathrm{~mL}$ of $0.05 \mathrm{M}$ phosphate buffer ( $\mathrm{pH} 4.5$ ) was added and the contents of the tube were shaken for $60 \mathrm{~min}$ and centrifuged at $4.000 \mathrm{rpm}$ for $20 \mathrm{~min}$ at $20^{\circ} \mathrm{C}$. Finally, the extracts obtained were filtered through a $0.45 \mu \mathrm{m}$ nylon filter (Waters, Milford, MA, USA) before being injected into the HPLC-DAD system.

Validation method. A validation study was performed in terms of specificity, linearity, accuracy (recovery), precision (repeatability and withinlaboratory reproducibility), limit of detection (LOD), and limit of quantification (LOQ).

The LOD is the lowest concentration of analyte that the analytical process can reliably differentiate from background levels, while the LOQ is the lowest concentration of analyte that can be quantified. These were determined using blank feed samples. LOD and LOQ values were calculated from signal-to-noise ratios $(\mathrm{S} / \mathrm{N})$ of 3 and 10 , respectively. The linearity of the method was evaluated by drawing standard solutions calibration curves with five concentration levels in triplicate. Repeatability was assessed by comparing the results of six replicates prepared on the same day at three different concentrations $(150,300$, and $500 \mathrm{mg} / \mathrm{kg})$. The procedure was repeated to determine within-laboratory reproducibility by comparing results from samples prepared and analysed on three different days. Standard deviations (SD) and coefficients of variation ( $\mathrm{CV}, \%)$ were calculated for each level. The recovery was 
calculated by the formula (measured level/fortified level) $\times 100 \%$. The overall mean concentration and CV were calculated as reproducibility. The selectivity of the method was found by comparing chromatograms of the blank samples with the chromatograms of the standards and samples with standard additions. Six blank feed samples from different sources were analysed in order to verify the absence of potential interfering endogenous compounds at the target analyte retention times and in this way to test the specificity. The uncertainty (U) was calculated as the ratio of coverage factor $(k=2)$ and SD of within-laboratory reproducibility, and expressed in percentages.

\section{Results}

The developed procedure was designed to obtain a qualitative method of determination of amoxicillin in medicated feedingstuffs. The reversed-phase Phenomenex Luna C18 and gradient of the phosphate buffer and acetonitrile were chosen to separate amoxicillin chromatographically within $18 \mathrm{~min}$. The best separation and peak shape were achieved using $0.01 \mathrm{M}$ phosphate buffer adjusted to $\mathrm{pH}$ 5.0. A typical chromatogram obtained from a spiked feed sample is presented in Fig. 3. Under selected conditions, AMO displayed high UV absorption at $202 \mathrm{~nm}$, while no interference of the matrix was observed (Figs 2 and 3).

A linearity and regression study was performed for DAD detection. The high correlation coefficient $\left(R^{2}=0.99\right)$ values indicated good correlations between AMO concentrations and peak areas. The linearity range was between 0.03 and $0.1 \mathrm{mg} / \mathrm{mL}$. Repeatability and within-laboratory reproducibility CVs were below $8 \%$. The results (Table 1) show that the assay recovery was in the range of $76.1 \%$ to $81.6 \%$. The accuracy was then calculated as the percentage of analyte recovery by the assay. LOD and LOQ values for AMO in animal feeds were $51.2 \mathrm{mg} / \mathrm{kg}$ and $103.0 \mathrm{mg} / \mathrm{kg}$, respectively. The expanded uncertainty was found to be less than $19.5 \%$. All parameters are presented in Table 1.

Table 1. Validation parameters of optimised HPLC-DAD method

\begin{tabular}{|c|c|}
\hline Validation parameters & Results \\
\hline Solvent STD regression equations & $y=80.695 x+392.76$ \\
\hline Coefficient of determination $\left(\mathrm{R}^{2}\right)$ & 0.99 \\
\hline \multicolumn{2}{|c|}{ Recovery (\%) } \\
\hline $150 \mathrm{mg} / \mathrm{kg}$ & 76.1 \\
\hline $300 \mathrm{mg} / \mathrm{kg}$ & 78.2 \\
\hline $500 \mathrm{mg} / \mathrm{kg}$ & 81.6 \\
\hline \multicolumn{2}{|c|}{ Repeatability (\%) } \\
\hline $150 \mathrm{mg} / \mathrm{kg}$ & 7.2 \\
\hline $300 \mathrm{mg} / \mathrm{kg}$ & 5.8 \\
\hline $500 \mathrm{mg} / \mathrm{kg}$ & 3.7 \\
\hline \multicolumn{2}{|c|}{ Within-laboratory reproducibility (\%) } \\
\hline $150 \mathrm{mg} / \mathrm{kg}$ & 7.6 \\
\hline $300 \mathrm{mg} / \mathrm{kg}$ & 6.8 \\
\hline $500 \mathrm{mg} / \mathrm{kg}$ & 5.3 \\
\hline $\mathrm{LOD}(\mathrm{mg} / \mathrm{kg})$ & 51.2 \\
\hline LOQ (mg/kg) & 103.0 \\
\hline $\mathrm{U}(\%)$ & 19.4 \\
\hline
\end{tabular}

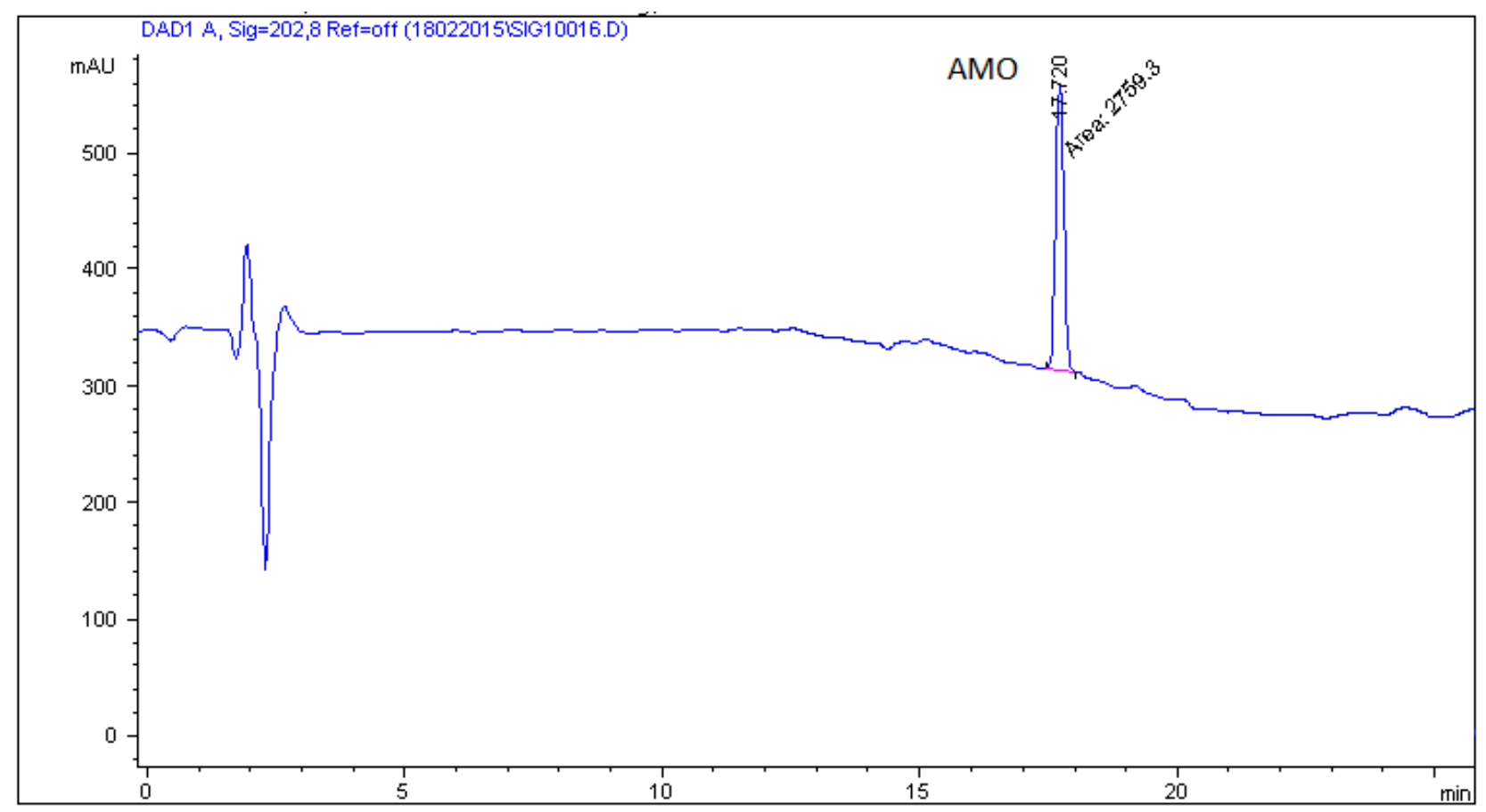

Fig. 1. HPLC-DAD chromatogram of AMO standard solution 


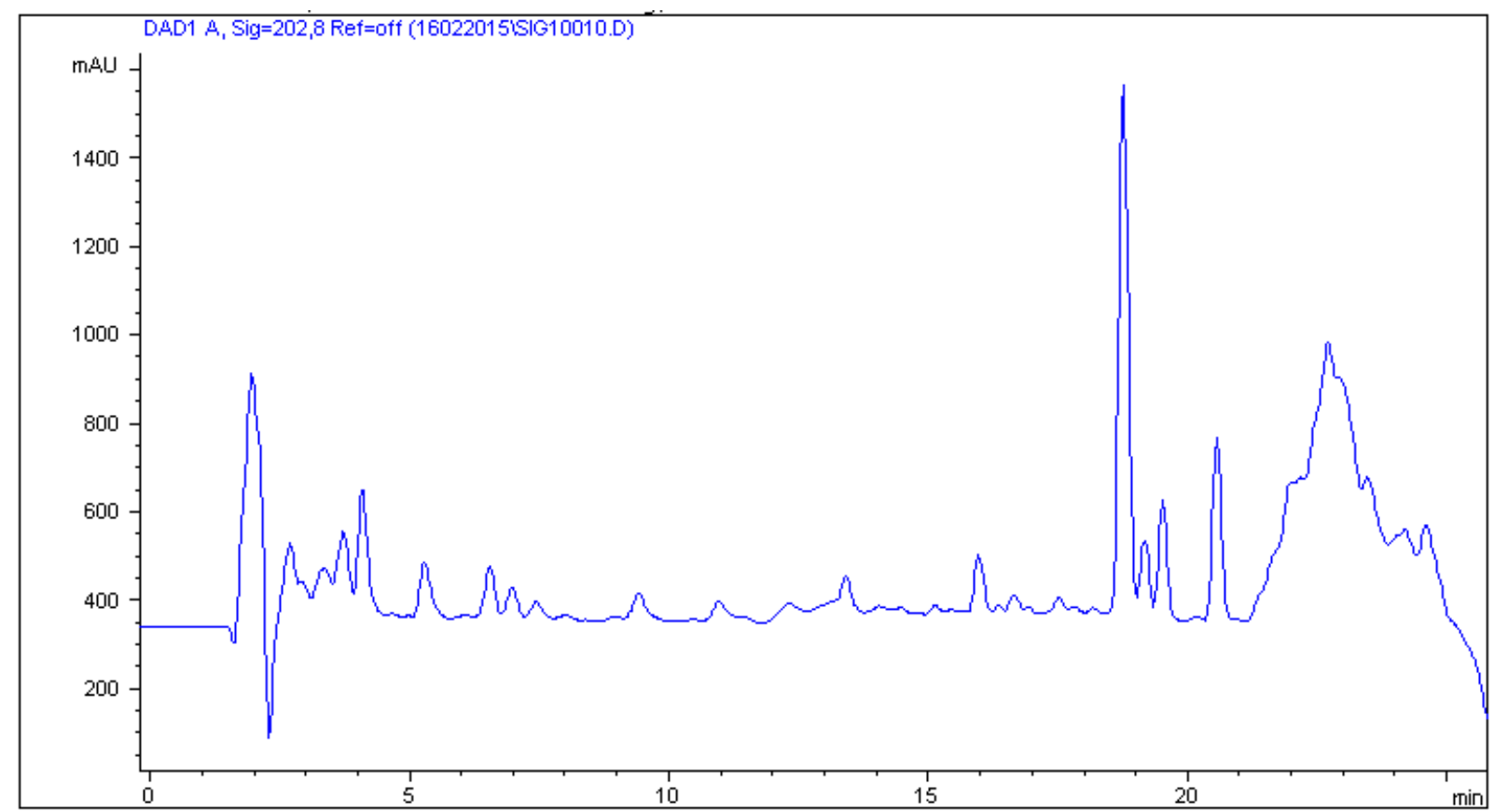

Fig. 2. HPLC chromatogram of blank pig feed

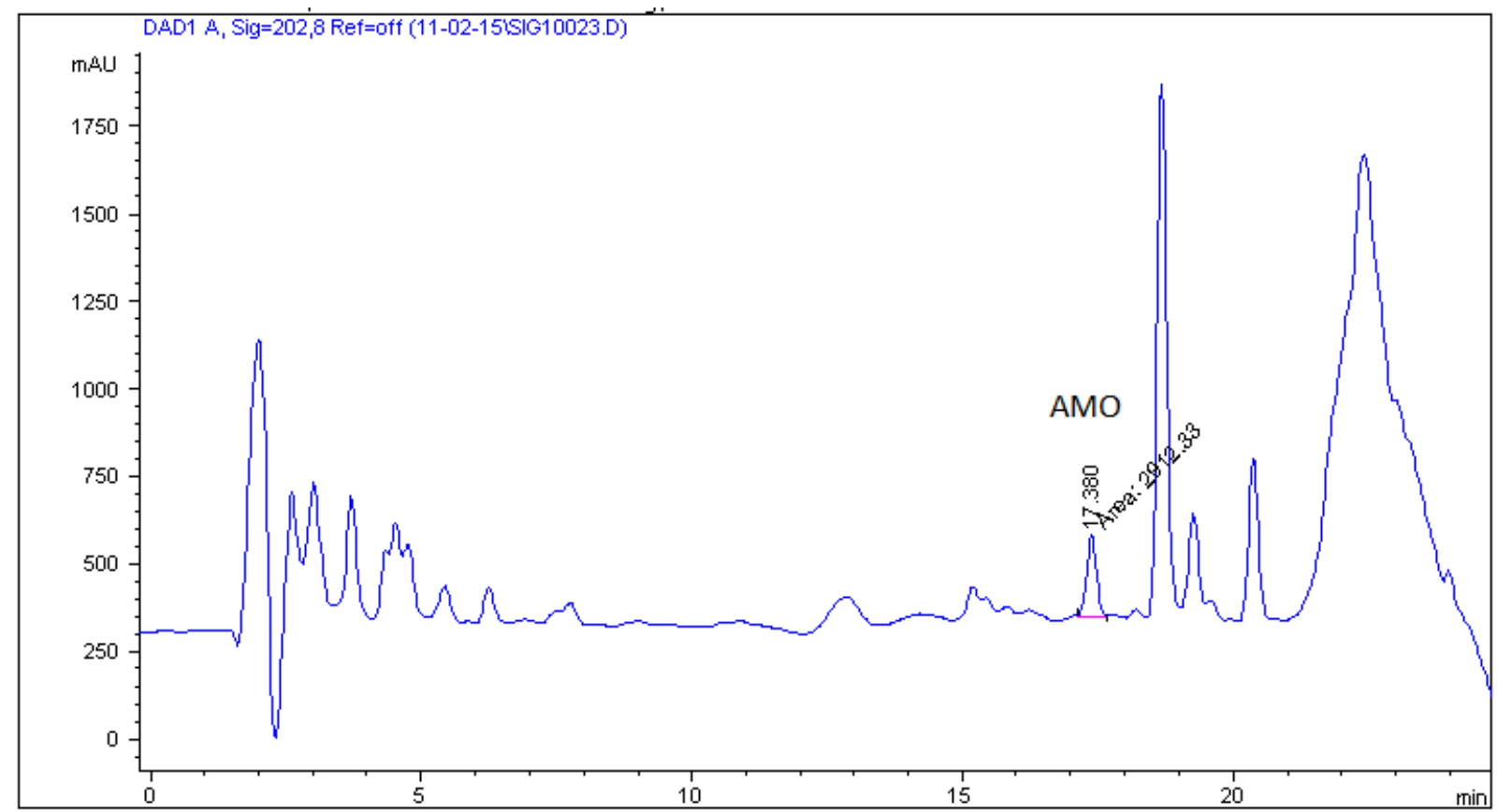

Fig. 3. HPLC chromatogram of blank pig feed spiked with AMO at a concentration of $150 \mathrm{mg} / \mathrm{kg}$

\section{Discussion}

This investigation aimed to develop a reversedphase HPLC method for the detection of AMO in medicated feedingstuffs and verification of their declared content.

To ensure the safety of food and feed, efficient methods are required for the simultaneous monitoring of contents of veterinary drugs in food and feed. A large number of available methods have been developed for determining penicillins from biological matrices, e.g. in milk, eggs, and plasma, but in the literature there is limited information about methods quantification of amoxicillin in medicated feedingstuffs with the use of the HPLC technique and extraction of AMO from the feed matrix $(4,9,12,15,16)$. Researchers have often used acetonitrile, acetonitrile and water mixture or $\mathrm{KH}_{2} \mathrm{PO}_{4}$ buffer for extraction amoxicillin from biological matrices at different $\mathrm{pH}$ ranges. Gamba and Dusi (12) and Benito-Peňa et al. (4) used an acetonitrile and water mixture $(25: 75 \mathrm{v} / \mathrm{v})$ for extraction of amoxicillin and ampicillin and amoxicillin and penicillin V from feed. LaCourse and Dasenbrock (16) opted for water and accelerated solvent extraction for 
extraction of amoxicillin, cephalosporin $\mathrm{C}$, cloxacillin, oxacillin, and penicillins $\mathrm{G}$ and $\mathrm{V}$. In an alternative approach, Luo et al. (21) and De Baere and Backer et al. (9) extracted amoxicillin from milk and feed samples using phosphate buffer.

To develop this method for the determination of AMO in medicated feed samples by a solid-liquid extraction technique, the parameters including sample weight, extraction time, extraction solvents, and $\mathrm{pH}$ value were studied. For the optimal extraction conditions, we tested 2 and $5 \mathrm{~g}$ sample weights, extraction solvents such as water/acetonitrile and phosphate buffer solution at $\mathrm{pH}$ ranging through 3,4 , $4.5,5$, and 6 , and shaking times between 20 and $60 \mathrm{~min}$. The final protocol for the extraction of amoxicillin was for 2 grams grinded feed samples to be extracted with $0.05 \mathrm{M}$ phosphate buffer, $\mathrm{pH} 4.5$, and shaken for $60 \mathrm{~min}$. These parameters allowed good recovery of AMO to be obtained without any additional purification step on SPE cartridges. The biggest advantages of the proposed method are its simplicity and robustness, which make the procedure time-saving and economical.

The mobile phase of the method for the determination of penicillins is usually phosphate buffer or trifluoroacetic acid with acetonitrile for the HPLC-UV or FLD techniques $(4,9,12,21,22)$ or formic acid in water and acetonitrile or methanol when penicillins are analysed by the LC-MS technique (3, 5-7, 9, 13, 14, 23, $29,33)$. In this method, chromatographic separation was optimised by testing variations of the mobile phase with different concentrations of potassium dihydrogen phosphate $(0.01 \mathrm{M}, 0.02 \mathrm{M}$, and $0.05 \mathrm{M})$ and $\mathrm{pH}$ between 4.0 and 6. Experimental results demonstrated that $0.01 \mathrm{M}$ phosphate buffer, adjusted to $\mathrm{pH} 5.0$ was the most suitable additive to enhance the peak resolution and sensitivity.

An important part of each chromatographic separation is to choose analytical columns, suitable for the particular group of compound packings. For the separation of amoxicillin from different kinds of matrices researchers commonly used $\mathrm{C} 18$ and $\mathrm{C} 8$ analytical columns $(4,30,32)$ or $\operatorname{ODS}$ column $(3,9,21)$. Column lengths of $150 \mathrm{~mm}$ or $250 \mathrm{~mm}$ were equally popular, but a packing of $5 \mu \mathrm{m}$ and column ID of $4.6 \mathrm{~mm}$ were the most common $(4,9,21,32)$. In this study, the best separation results were achieved on a Luna C18 column with $0.01 \mathrm{M}$ phosphate buffer in water $(\mathrm{pH} 5.0)$ and acetonitrile. The use of gradient elution gave a much better separation of the analysed compound. The developed method gave good results for both samples prepared in-house (spiked with the appropriate levels of AMO) and those delivered by manufacturers. Figs 1, 2, and 3 show chromatograms of standard solution, blank feed, and feed samples spiked with AMO at a concentration of $150 \mathrm{mg} / \mathrm{kg}$.

The proposed HPLC method is simple, economic, accurate, reproducible, and useful for determination of AMO in medicated feedingstufs. The extraction of the antibiotic is based on a simple solid-liquid extraction and no clean-up step is necessary. After filtration, the extracts can be directly injected into the HPLC-DAD system. The presented method has good repeatability and within-laboratory reproducibility, as indicated by the CVs for both being less than $8 \%$. The satisfactory results of validation proved that the method is efficient and precise. Therefore, this method can be applied in official quality control procedures to verify the producers' declarations of the amount of the active substances in medicated feedingstuffs and their homogeneity.

Conflict of Interests Statement: The authors declare that there is no conflict of interests regarding the publication of this article.

Financial Disclosure Statement: The study was financially supported by the National Veterinary Research Institute, Puławy, Poland

Animal Rights Statement: None required.

\section{References}

1. Ang C.Y.W., Luo W.H., Hansen E.B., Freeman J.P., Thompson H.C. Jr.: Determination of amoxicillin in catfish and salmon tissues by liquid chromatography with precolumn formaldehyde derivatization. J AOAC Intern 1996, 79, 389-396.

2. Association of American Feed Control Officials (AAFCO): Reference method AOAC 967.41(Code AAFCO 074.00) in Feed Check Samples, 2006, AAFCO, Champaign, IL, USA.

3. Becker M., Zittlaub E., Petza M.: Residue analysis of 15 penicillins and cephalosporins in bovine muscle, kidney, and milk by liquid chromatography-tandem mass spectrometry. Anal Chim Acta 2004, 520, 19-32.

4. Benito-Pena E., Urraca J.L., Moreno-Bondi M.C.: Quantitative determination of penicillin $\mathrm{V}$ and amoxicillin in feed samples by pressuurised liquid extraction and liquid chromatography with ultraviolet detection. J Pharm Biomed Anal 2009, 49, 289-294.

5. Bo W., Maoda P., Xing X., Min Z., Kaizhou X., Yangyang Z., Xia Z., Ya'juan W., Ran W., Haiqing W., Genxi Z., Guojun D., Jinyu W.: Quantitative analysis of amoxicillin, amoxicillin major metabolites, and ampicillin in chicken tissues via ultraperformance liquid chromatography-electrospray ionization tandem mass spectrometry. Food Anal Methods 2017, 10, 3292 3305.

6. Bogialli S., Capitolino V., Curini R., Di Corcia A., Nazzari M., Sergi M.: Simple and rapid liquid chromatography-tandem mass spectrometry confirmatory assay for determining amoxicillin and ampicillin in bovine tissues and milk. J Agri Food Chem 2004, 52, 3286-3291.

7. Chuangji L., Hai W., Yanbin J., Zhenxia D.: Rapid and simultaneous determination of amoxicillin, penicillin $\mathrm{G}$, and their major metabolites in bovine milk by ultra-high-performance liquid chromatography-tandem mass spectrometry. J Chromatogr B 2011, 879, 533-540.

8. Cutting J.H., Hurlbut J.A., Sofos J.N.: Quantitation of penicillin $\mathrm{G}$ in medicated premix feeds by micellar electrokinetic capillary chromatography. J AOAC Inter 1997, 80, 951-955.

9. De Baere S., De Backer P.: Quantitative determination of amoxicillin in animal feed using liquid chromatography with tandem mass spectrometric detection. Anal Chim Acta 2007, 586, 319-325. 
10. European Medicines Agency: 8th ESVAC Report 2018. Sales of veterinary antimicrobial agents in 30 European countries in 2016 Trends from 2010 to 2016. London, 2018.

11. Fernandez-Torres R., Olias Consentino M., Bello M.A., Callejon M.: Simultaneous determination of 11 antibiotics and their main metabolites from four different groups by reversedphase high-performance liquid chromatography-diode arrayfluorescence (HPLC-DAD-FLD) in human urine samples. Talanta 2010, 81, 871-880.

12. Gamba V., Dusi G.: Liquid chromatography with fluorescence detection of amoxicillin and ampicillin in feeds using pre-column derivatization. Anal Chim Acta 2003, 483, 69-72.

13. Heller D.N., Ngoh M.A.: Electrospray ionization and tandem ion trap mass spectrometry for the confirmation of seven $\beta$-lactam antibiotics in bovine milk. Rapid Communicat Mass Spectrometry 1998, 12, 2031-2040.

14. Hui L., Xi X., Yanan X., Shusheng T., Xilong X., Jiancheng L., Jianzhong S.: Simultaneous determination of amoxicillin and prednisolone in bovine milk using ultra-high performance liquid chromatography tandem mass spectrometry. J Chromatogr B 2012, 900, 59-63.

15. Krasucka D., Kowalski C.J., Osypiuk M.: Determination of amoxicillin in pig plasma by liquid chromatography with fluorescence detection. Bull Vet Inst Pulawy 2011, 55, 771-775.

16. LaCourse W.R., Dasenbrock C.O.: Pulsed electrochemical detection of sulfur-containing antibiotics following high performance liquid chromatography. J Pharm Biomed Anal 1999, 19, 239-252.

17. Lal J., Paliwal J.K., Grover P.K., Gupta R.C.: Determination of ampicillin in serum by high-performance liquid chromatography with precolumn derivatization. J Chrom B 1994, 655, 142-146.

18. Li Y.M., Van Schepdael A., Zhu Y., Roets E., Hoogmartens J.: Development and validation of amoxicillin determination by micellar electrokinetic capillary chromatography. J Chrom A 1998, 812, 227-236.

19. Lirui S., Long fei J., Xing X., Kaizhou X., Jianfeng W., Jianyu L., Lulu C., Genxi Z., Guojun D., Jinyu W.: Quantitative analysis of amoxicillin, its major metabolites and ampicillin in eggs by liquid chromatography combined with electrospray ionization tandem mass spectrometry. Food Chem 2016, 192, 313-318.

20. Lott A.F., Smither R., Vaughan D.R.: Antibiotic identification by high-voltage electrophoresis bioautography. J AOAC Inter 1985, 68, 1018-1020.

21. Luo W., Hansen E.B. Jr., Ang C.Y.W., Deck J., Freeman J.P., Thompson H.C. Jr.: Simultaneous determination of amoxicillin and ampicillin in bovine milk by HPLC with fluorescence detection. J Agri Food Chem 1997, 45, 1264-1268.

22. Luo W.H., Ang C.Y.W., Thompson H.C. Jr.: Rapid method for the determination of ampicillin residues in animal muscle tissues by high-performance liquid chromatography with fluorescence detection. J Chrom B 1997, 694, 401-407.

23. Makeswaran S., Patterson I., Points J.: An analytical method to determine conjugated residues of ceftiofur in milk using liquid chromatography with tandem mass spectrometry. Anal Chim Acta 2005, 529, 151-157.

24. Mitchell J.M., Griffiths M.W., McEven S.A., McNab W.B., Yee A.J.: Antimicrobial drug residues in milk and meat: causes, concerns, prevalence, regulations, tests, and test performance. J Food Protect 1998, 61, 742-756.

25. Pajchel G., Pawlowski K., Tyski S.: CE versus LC for simultaneous determination of amoxicillin/clavulanic acid and ampicillin/sulbactam in pharmaceutical formulations for injections. J Pharm Biomed Anal 2002, 29, 75-81.

26. Patyra E., Kwiatek K.: Development and validation of multiresidue analysis for tetracycline antibiotics in feed by high performance liquid chromatography coupled to mass spectrometry. Food Add Contamin Part A 2017, 34, 1553-1561.

27. Regulation (EU) 2019/4 of the European Parliament and of the Council of 11 December 2018 on the manufacture, placing on the market and use of medicated feed, amending Regulation (EC) No 183/2005 of the European Parliament and of the Council and repealing Council Directive 90/167/EEC (Text with EEA relevance). OJ L 4, 62, 1-23.

28. Reyns T., Cherlet M., Baere S.D., Backer P.D., Croubels S.: Tissue depletion of amoxicillin and its major metabolites in pigs: influence of the administration route and the simultaneous dosage of clavulanic acid. J Chrom B 2008, 861, 108-116.

29. Riediker S., Stadler R.H.: Simultaneous determination of five $\beta$-lactam antibiotics in bovine milk using liquid chromatography coupled with electrospray ionization tandem mass spectrometry. Anal Chem 2001, 73, 1614-1621.

30. Stolker A.A.M., Rutgers P., Oosterink E., Lasaroms J.J.P., Peters J.R.J.B., van Rhijn A., Nielen M.W.F.: Comprehensive screening and quantification of veterinary drugs in milk using UPLC-ToF-MS. Anal Bioanal Chem 2008, 391, 2309-2322.

31. Tollefson L., Miller M.A.: Antibiotic use in food animals: controlling the human health impact. J AOAC Inter 2000, 83, 245-254.

32. Xie K., Jia L., Xu D., Guo H., Xie X., Huang Y., Chen X., Bao W., Dai Gu., Wang J.: Simultaneous determination of amoxicillin and ampicillin in eggs by reversed-phase highperformance liquid chromatography with fluorescence detection using pre-column derivatization. J Chrom Sci 2012, 50, 620-624.

33. Yuan L., Kui Z., Jian Fen W., Xiaoyong H., Guanlin W., Congying L., Jie C., Shuangyang D.: Simultaneous detection and comparative pharmacokinetics of amoxicillin, clavulanic acid, and prednisolone in cows' milk by UPLC-MS/MS. J Chromatogr B 2016, 1008, 74-80. 